\title{
Transformation of the water system of the Education City in Doha into a smart water system
}

\author{
Abdallah AL-NAEMI ${ }^{1,2}$ \& Isam SHAHROUR ${ }^{I}$ \\ ${ }^{1}$ Laboratoire de Génie Civil et géo-Environnement, Université de Lille, 5900 Lille, France \\ ${ }^{2}$ Qatar Foundation, Doha, Qatar
}

\begin{abstract}
This paper presents the transformation of the water system of the Education City in Doha (Qatar) into a smart water system. This city covers an area of $14 \mathrm{~km}^{2}$ and includes 80 buildings. The water system provides drinking, irrigation and fire protection services. It suffers from the use of fragmented management systems and from a lack of real-time monitoring, which result in a deterioration of efficiency of the water system and users' information The paper describes the water system and then the architecture of the smart water solution and its use for leak detection, water quality control and operation safety.
\end{abstract}

Key words: Smart Water, Leak, contamination, irrigation, fire-protection, Education City

\section{Introduction}

This paper concerns the transformation of the water system of the Education City in Doha (Qatar) into a smart water system. The Education City covers an area of $14 \mathrm{~km}^{2}$ with 80 buildings and facilities. It was constructed by successive extensions of an existing area. As a result, the city uses fragmented tools for utilities management, which results in losses in efficiency and an increase in expenses.

Today, the modernization of water utilities becomes a "must" in order to reduce water losses, improve asset management, reduce water contamination risk and improve the quality of water services. According to several researches, the smart water concept constitutes an excellent solution to achieve this goal (Storey et al. 2011, Lambrou 2014, Farah \& Shahrour 2017, Abou Rjeily et al. 2017, Mishra et al. 2018, Saab et al. 2018, Liu et al. 2019). This solution is based on a comprehensive real-time monitoring of the water utilities, share of data with concerned stakeholders and use of advanced tools such as Artificial Intelligence for data analysis and the transformation of collected data into operation data that ensure the optimal management of the water system.

This paper presents the transformation of the complex water system of the Education City into a smart water system. It presents successively the Education City, the water system and the transformation of this system into a smart system.

\section{Presentation of the water system in the Education City}

\subsection{Presentation of the Education City}

Figure 1 shows the development of the Education City in Doha. In 2002, it covered an area of $3 \mathrm{~km}^{2}$, then it expanded to $6.1 \mathrm{~km}^{2}$ in 2003 and to $7.5 \mathrm{~km}^{2}$ in 2004. In 2016, it covered an area of $14 \mathrm{~km}^{2}$. Figure 2 shows the master plan of the Education City. It is composed of 2 zones: North and South zones. Because of historical factors, the infrastructures of these two zones are independent. The Education City hosts around 80 buildings, which are used for (i) Higher Education (10 buildings), (ii) Pre-Education (3 buildings), (iii) Technology (9 buildings, (iv) Social services \& 
activities (14 buildings), (v) Culture, arts \& heritage (5 buildings), (vi) Housing \& hotel (6 buildings)and technical services ( 28 buildings).

\subsection{Presentation of the water system}

The water system provides drinking water, fire protection and irrigation services. Eight central plants are used as the main hub for water operation. Figure 3 shows the distribution of the central plants. Each zone of the Education City is served by four central plants. Figure 4 illustrates architecture of the water system. The central plant is directly supplied from the water company (Kahramaa). A water meter records the water supply of the central plant. Water is stored in a tank, which has a capacity to cover water needs for 2 days. Pumps are used for water transportation to the consumption sections. A utility tunnel hosts pipes for drinking water, irrigation and fire protection. Flow meters were installed to record buildings' water consumption. Each central plant uses a dedicated water management system.

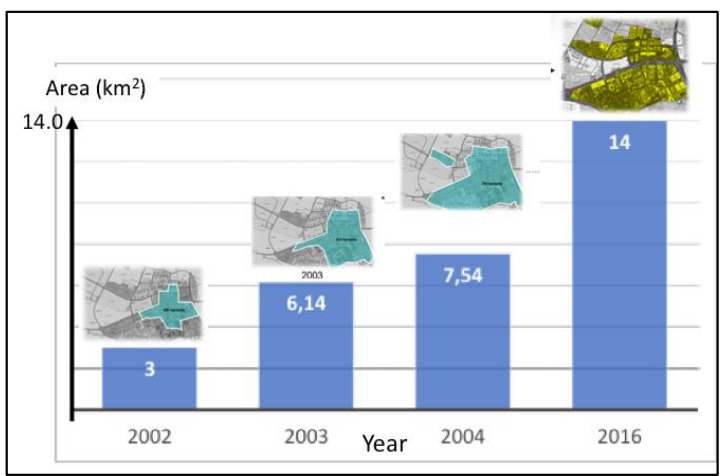

Figure 1: Stages of development of the Education City

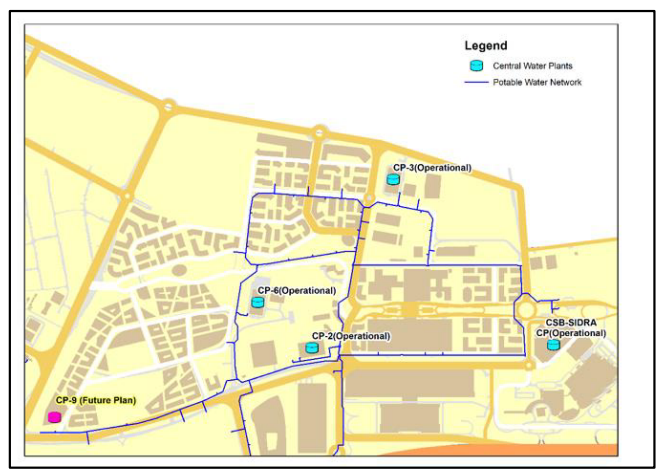

North zone

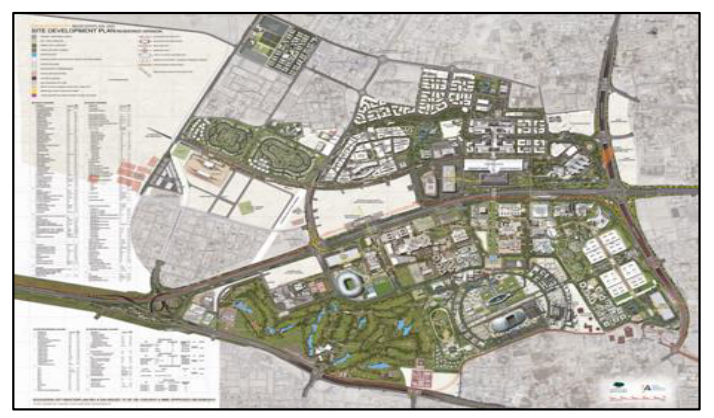

Figure 2. Master plan of the Education City

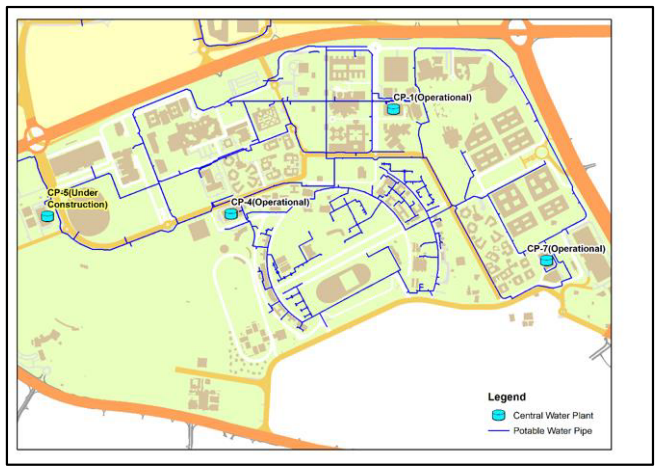

South zone

Figure 2. Location of the central plants in the Education City 


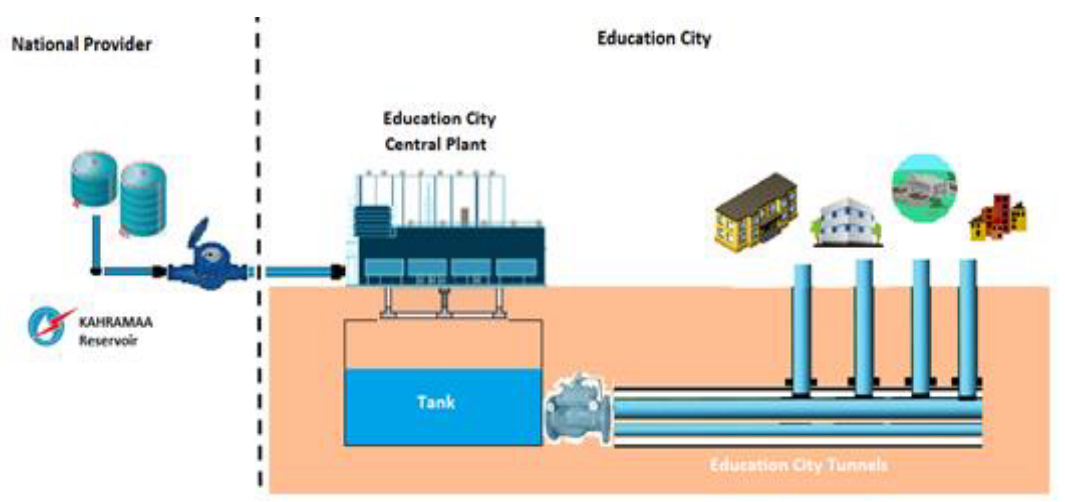

Figure 3: Organization of the water system of the Education City

\section{Smart water solution}

\subsection{Solution architecture}

The transformation of the water system of the Education City into a smart water system requires an integrated approach with a unique smart platform, which ensures data collection, data storage, data analysis, data visualization and operation control. The smart water system presented in this section is based on researches and achievements of SunRise project conducted at Lille University (Shahrour et al. 2017, Farah and Shahrour 2017, Saab et al. 2018 2018) as well as the outcome of the European project SmartWater4Europe (SW4EU, 2017).

The architecture of the smart water solution is presented in Figure 4. It includes a platform, which coordinates operations related to the smart management of the water system and an information system, which stores:

- Assets data of the water infrastructures, which are collected using GIS. All the components and attributes are integrated in the same system and could be visualized in GIS environment

- Data collected by the sensors, which concern the system security and optimal operation, such as water flow, water pressure and water quality.

- Maintenance and operation data.

Data analysis is conducted using engineering software such as those used in leak detection, contamination detection, operation control (pressure, flow, temperature,...). Artificial Intelligence is used for data analysis. It allows to learn from historical data, to identify operating trends and interaction as well as abnormal events and actions to be taken in case of an abnormal event. It allows also the optimal management of the water system.

Data visualization is conducted using GIS software as well as specific software to visualize the operating conditions, incidents and maintenance.

The results of data analysis are turned into operationl data (security and optimization) and transmitted to the water system through command equipment such as electronic valves, switches, motors,... 


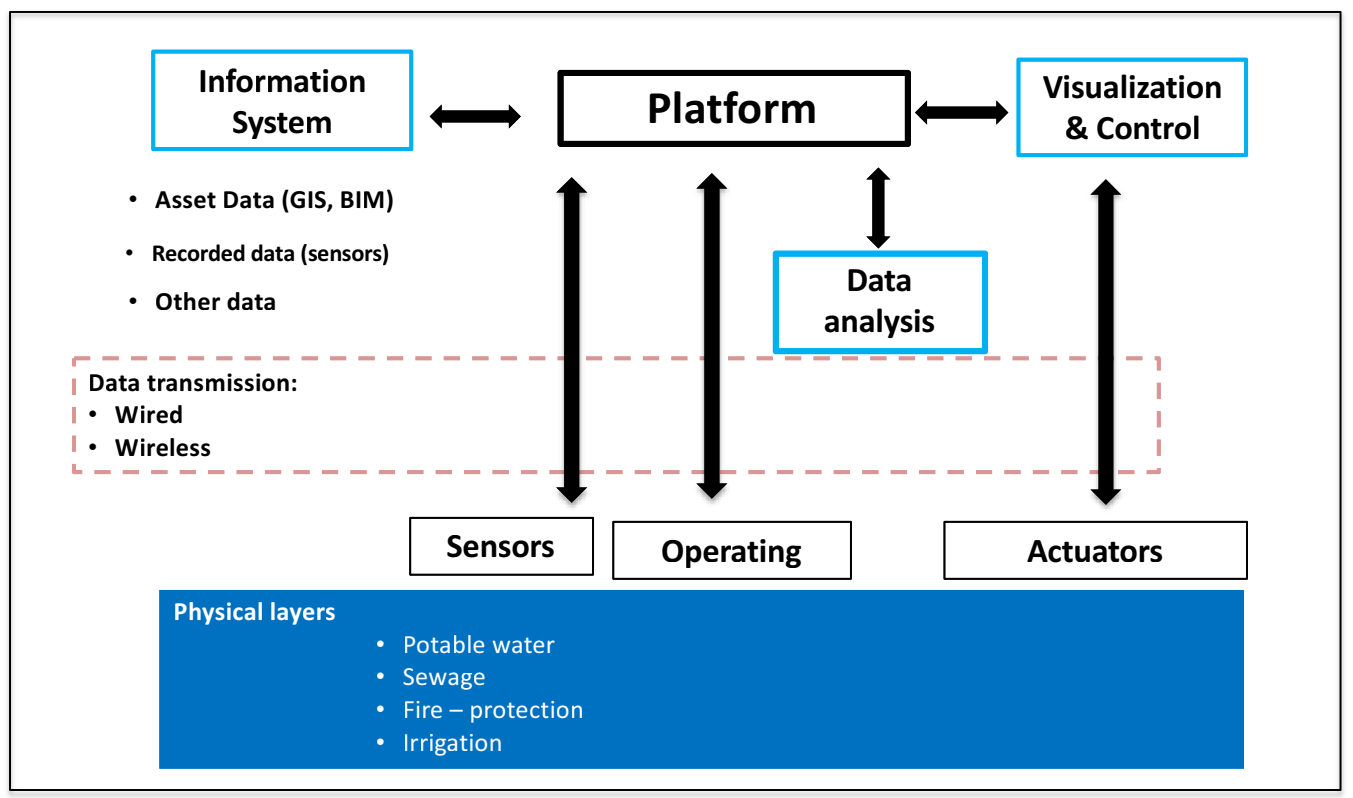

Figure 4: Architecture of the smart water solution

\subsection{Smart drinking water}

The smart drinking water system aims at improving the detection of water leak and contamination and operating adequate measurments in case of any abnormal event.

For a rapid detection of the water leak, the water system is monitored using Automatic Meter Readings (AMRs) which measure water flow and then transmit readings to a data collector and then to a smart water platform. AMR are installed at the water supply of the central plants (Kahramaa water meter), the water tank outlet and the water supply of buidings and other facilities (Figure 5). A level water sensor is installed in the tank in order to control the tank's filling-up.

The AMR at the supply section of the central plant allows to control Kahramaa billings.

Leak in the water tank could be controlled from the AMR of Kahramaa supply, AMR at the tank outlet and the water level sensor.

Leak in the water network could be determined using the DMA method (District Metering Areas), which consists in checking the balance between the water supply (tank outlet AMR) and the totality of the water consumption in buildings (sum of AMR of buildings in the DMA).

Leak in buildings could be determined using the Artificial Intelligence (AI). For each building, the consumption profile is established from historical data. Real time readings from AMR are then compared to consumption profile. In case of a gap with between the readings and the consumption profile, a leak event is created with a severity degree related to the amount of the gap between the profile and the readings.

Water quality is controlled using S::CAN station at the outlet of the water tank. This station records the following water quality parameters: UV, Turbidity, TOC, DOC, Temperature, Color, $\mathrm{pH}$, Conductivity, Temperature and Chlorine. Data are recorded at 2 minutes interval and transmitted to the Education City Platform. Data analysis is based on the deviation of readings from parameters' base-line. The deviation from the base-line indicates events related to water quality change. For the determination of the contamination origin, Saab et al. (2018) proposed to use a combination of data recorded by the Chlorine and Turbidity sensors. 


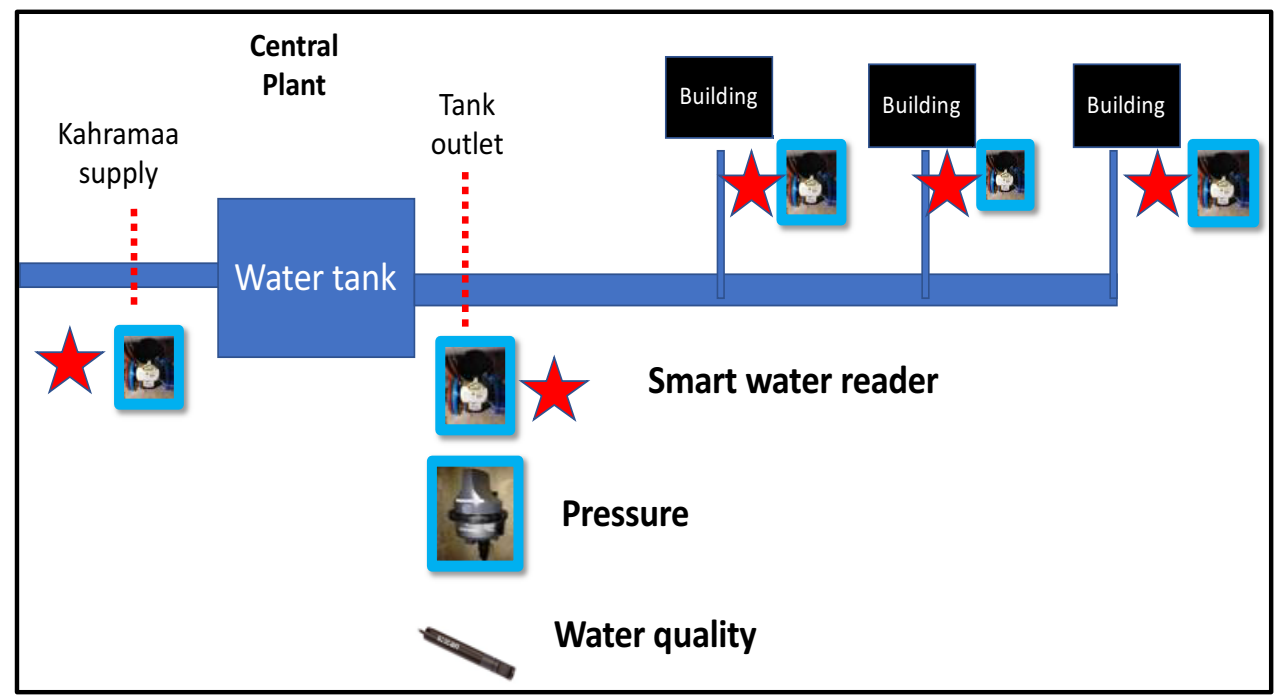

Figure 5: Smart monitoring of the drinking water system (Education City, Doha)

\subsection{Irrigation system}

The smart irrigation system aims at detecting water leak and optimization of the irrigation process. The leak detection system is similar to that used in the drinking water system (Figure 6).

The optimization of the irrigation service is based on the use of a monitoring system, which controls the soil moisture in the plants' root zone in order to ensure water plants' need. Sensors are used to measure the soil moisture and to transmit data to the smart water platform. The water platform conducts data analysis using historical and real-time data, weather prevision and the plants irrigation needs and then it controls the irrigation operation using electronic valves.

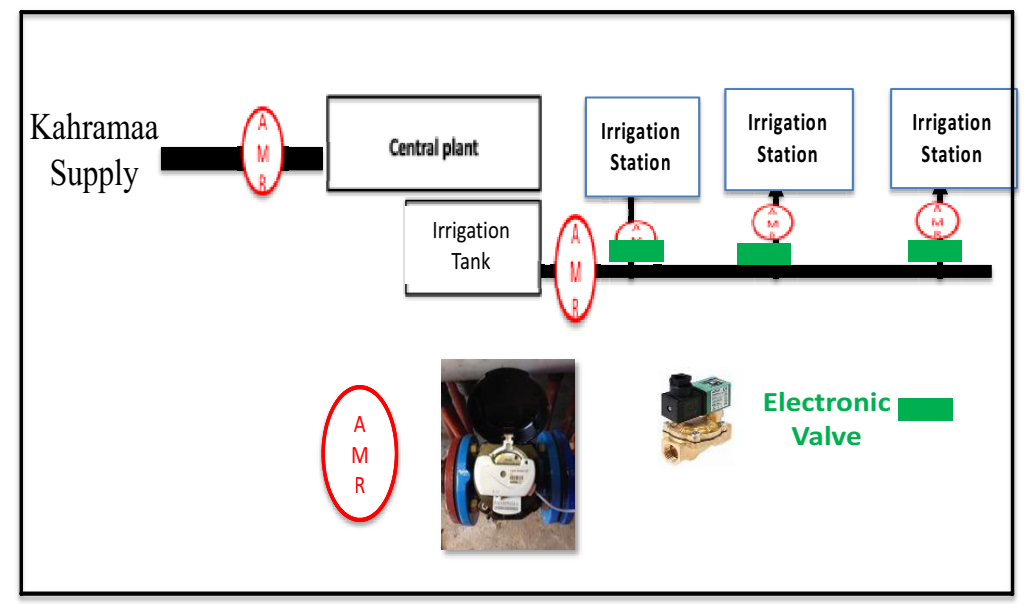

Figure 6: Smart monitoring of the irrigation system (Education City, Doha) 


\subsection{Fire water system}

The smart fire protection system aims at the detection of water leak and the control of the hydrants pressure. The leak detection system is similar to that presented in the drinking water system (Figure 7).

Pressure sensors are installed in the hydrants for a real-time control the water pressure. In the case of a drop in the water pressure, alerts are sent to ithe management and mainteance teams.

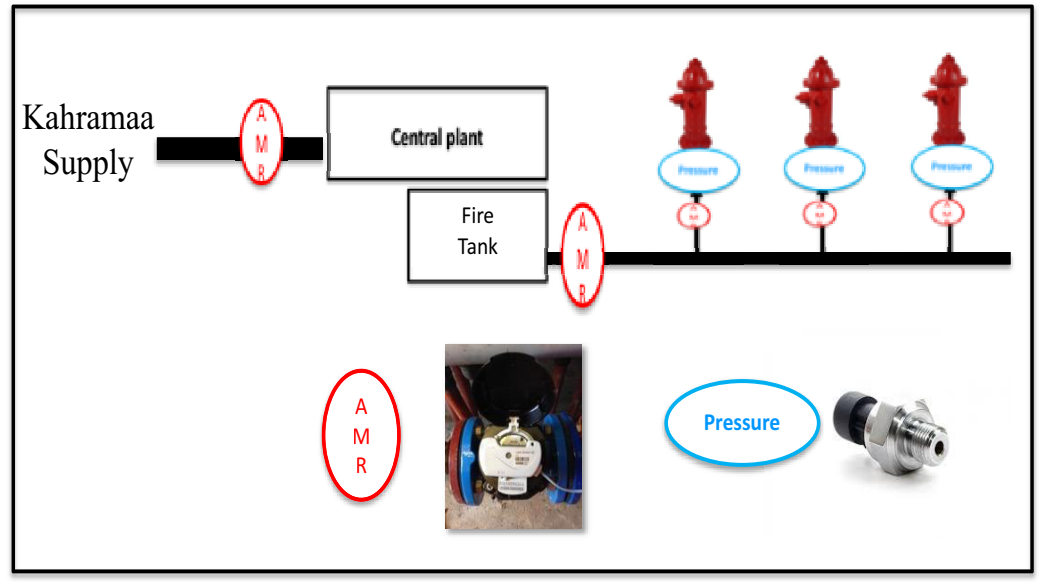

Figure 7: Smart monitoring of the fire-protection system (Education City, Doha)

\section{Conclusion}

This paper presented the transformation of the water system of the Education City in Doha into a smart water system, that ensures real-time monitoring of the drinking water, irrigation and fire protection systems. A smart water platform is used for data collection, data storage, data analysis and water system control.

The smart water system allows a rapid detection of the water leak. In addition, it allows a real-time control of the water quality in the drinking water system and the pressure drop in the fire protection system as well as the optimization of the irrigation process.

This system offers the possibility to inform users about the water service in the Education City and about the impact of strategies implemented for the sustainable water management. Consequently, it contributes to reinforce users' involvement in the implementation of sustainable water management strategies.

\section{References}

1. Abbas, O., Y. A. Rjeily, M. Sadek \& I. Shahrour (2017) A large-scale experimentation of the smart sewage system. Water and Environment Journal, 31, 515-521.

2. Abou Rjeily, Y., O. Abbas, M. Sadek, I. Shahrour \& F. H. Chehade (2017) Flood forecasting within urban drainage systems using NARX neural network. Water Science and Technology, 76, 2401-2412.

3. Farah E., \& Shahrour I. (2017) Leakage Detection Using Smart Water System: Combination of Water Balance and Automated Minimum Night Flow. Water Resources Management, 31(15):4821-4833.

4. Lambrou T. P., Anastasiou C. C., Panayiotou C. G. \& Polycarpou,M. M. (2014) A low-cost sensor network for real-time monitoring and contamination detection in drinking water distribution systems. IEEE sensors journal, 14(8): 2765-2772. 
5. Liu P., Wang J., Sangaiah AK., Xie Y. 5 and Yin X (2019). Analysis and Prediction of Water Quality Using LSTM Deep Neural Networks in IoT Environment. Sustainability 2019, 11, 2058.

6. Mishra, D.R., D’Sa E.J., Mishra S. Preface (2018) Remote sensing of water resources. Remote Sens. 2018, 10,115 .

7. Saab C., Farah E., Shahrour I., Hage-Chehade F., \& Ounaies, S. (2018) Use of the smart technology for water quality control: feedback from large-scale experimentation. Analog Integrated Circuits and Signal Processing, Springer, 96(2):327-335.

8. SW4EU (2017) SmartWater4Europe: Demonstration of integrated smart water supply solutions at 4 sites across Europe. European project final report. Grant Agreement no 619024.

https://cordis.europa.eu/docs/results/619/619024/final1-final-report-sw4eu-v2-0-20180228.pdf

9. Shahrour I., Abbas O., Abdallah A., Abou Rjeily Y. Afaneh, A., Aljer A., (2017). Lessons from a LargeScale Demonstrator of the Smart and Sustainable City. In A. Brdulak, \& H. Brdulak (Eds.), Happy City How to Plan and Create the Best Livable Area for the People (pp. 193-206). Springer International Publishing.

10. Storey M.V.; van der Gaag B.; Burns, B.P. (2011) Advances in on-line drinking water quality monitoring and early warning systems. Water Res. 2011, 45, 741-747. 